Available online on 15.12.2020 at http://jddtonline.info
Open Access to Pharmaceutical and Medical Research
(C) 2011-18, publisher and licensee JDDT, This is an Open Access article which permits

Open $\odot$ Access

Review Article

\title{
Role of MMP-9 in Diabetic Retinopathy
}

\author{
${ }^{1}$ Mastari Ekawaty Suryani, ${ }^{2 *}$ Widjaja Sry Suryani, ${ }^{3}$ Siregar Yahwardiah, ${ }^{4}$ Sari Mutiara Indah \\ 1,2,3 Master Program of Biomedical Science, Faculty of Medicine, Universitas Sumatera Utara, Indonesia \\ 2,3,4 Department of Biochemistry, Faculty of Medicine, Universitas Sumatera Utara, Indonesia
}

\begin{abstract}
Diabetic retinopathy is a common neurovascular complication of diabetic that strike a third of diabetic patients worldwide. Complex mechanism of biomolecules including enzyme and cytokines is related to oxidative stress of constant hyperglycaemia. Vascular permeability damage resulting from endothelial leakage and apoptosis of Muller cell is the main mechanism of retinal damage. MMPs as endopeptidases have an important role in angiogenesis process of retinopathy by working with various molecules of growth factors, chemokines, cytokines and cell adhesion molecules. MMP-9 has been widely shown to be associated with inflammation, blood-retinal barrier disruption, cell apoptosis and neovascularization in the diabetic retinopathy pathomechanism.
\end{abstract}

Keywords: Diabetic retinopathy; MMP; MMP-9; Blood-retinal barrier

Article Info: Received 05 Oct 2020; Review Completed 23 Nov 2020; $\quad$ Accepted 04 Dec 2020; Available online 15 Dec 2020

Cite this article as:

Mastari ES, Widjaja SS, Siregar Y, Sari MI, Role of MMP-9 in Diabetic Retinopathy, Journal of Drug Delivery and Therapeutics. 2020; 10(6-s):122-124 http://dx.doi.org/10.22270/jddt.v10i6-s.4635

*Address for Correspondence:

Sry Suryani Widjaja, Department of Biochemistry, Faculty of Medicine, Universitas Sumatera Utara, Indonesia

\section{INTRODUCTION}

Diabetic retinopathy is a microvascular complication suffered by $35,4 \%$ of diabetic patients worldwide and became one of major vision-threatening disease ${ }^{1}$. Generally, the prevelance of retinopathy diabetic in Western countries is higher than in Asia. In Asia, the highest prevalence was found in Singapore $(33,9 \%)^{2}$. Potential effect of retinopathy in blindness is shown by high prevalence of diabetic cases which tend to increase every year 1,3 .

Retinopathy diabetic starts when constant hyperglycemia condition occurs in 2 to 6 weeks of diabetes onset. It tends to develop slowly and silently and major cases are detected in severe conditions 1. Duration of diabetes and glycemic control is the main risk factor of this complication. Diabetic classification, hypertension, obesity, dyslipidemia, and other complication of diabetes are other influencing factor of retinopathy development 4. Other than oxidative stress, MMPs, protein kinase $\mathrm{C}$ and polyol pathways have synergies role in retinopathy pathobiology 5 .

As an endopeptidase, MMP-9 are associated with inflammation, angiogenesis and anti-angiogenesis, mitochondrial dysfunction and also cell apoptosis in retinopathy diabetic 6,7 . In constant hyperglycemic condition, MMP-9 has caused blood-retinal barrier damage 8,9. Decreasing of cell viability and apoptosis of retina Muller cell was found related to the MMP-9 level increased ${ }^{8}$.

\section{DIABETIC RETINOPATHY}

Diabetic retinopathy is retinal chronic inflammation and neurodegeneration affected by local and systemic metabolic changes of diabetic condition. The process occur synergistically in neurovascular in the retina environment by involving large and small blood vessel of neuropiles 10-12.

The risk of retinopathy is proportionally increases with longer duration of diabetes. Of DM type 1 patient, the risk is $25 \%$ after 5 years and increase up to $80 \%$ after 15 years. Retinopathy is suffered by $40 \%$ insulin-dependent and $24 \%$ non-insulin dependent of type 2 diabetic patients. Each group risk has increased up to $84 \%$ and 53\% respectively after 19 years of diabetes 13. Once developed, glycemic control is assumed more importance for retinopathy process than duration of diabetes 14. Prolonged hyperglycaemia impact on cellular metabolism changes and macromolecules modification that results in structural and functional tissue alteration 15 .

Diabetic retinopathy is classified based on vascular lesions found on ophthalmology examination. Non-proliferative diabetic retinopathy (NPDR) stages are characterized by vascular distortion, retinal hemorrhage, microaneurysm and lipid exudates. Proliferative diabetic retinopathy (PDR) stage is marked by fragile new vessel which may lead to praretinal or vitreous bleeding. Another important category is diabetic macular edema (DME) which shown by abnormal retina thickening and macular cystoid edema resulted from fluid accumulation in retinal nerve tissue 16,17. 
In normal condition, endothelial vascular cell, pericyte, astrocyte, Muller cell and neuron are working together forming blood-retinal barrier ensuring retinal blood flow. This barrier maintains ionic environment for synaptic transmission and adaptive responses in visual function 10 .

Retina microvascular damage mediated by constant hyperglycemic condition begins retinopathy process. Increased polyol and hexosamine pathway flux, oxidative stress, protein kinase $\mathrm{C}$ activation, and AGEs are also followed by overproduction of free radical in mitochondria. These conditions aggravate chronic inflammation and oxidative stress in retinal microenvironment 11,15. The vascular response of coupling neurovascular and gliaendothel disruption in earlier process, decrease dilation response of venules and arterioles ${ }^{16}$. Other than vascular components of endothelial cells and pericytes, retinal neuron cells, macroglia (Muller cells and astrocytes), microglia, immune cells and retinal pigmented epithelium (RPE) are also involved in these inflammation ${ }^{16}$. Impact of oxidative stress and inflammatory cytokines also activate microglia in retinal perivascular which result in neurotoxicitity and tissue impairment 18 .

Decreased retinal perfusion and blood-retinal barrier damage in diabetic retinopathy enables cytokines and chemokines entering retina tissue and aggravate neurodegeneration of glutamate production 16,19. Occludin degradation by MMP-9 in retina tight junction attenuate vascular permeability ${ }^{20}$. Other neurotoxic production such as caspase-3, glutamate and MMPs also lead to neuron, pericyte and endothelial dysfunction 21.

\section{MATRIX METALLOPROTEINASES (MMPS)}

MMPs are endopeptidase that may work on various substrates such as soluble, integral or extracellular protein and proteoglicans. MMPs also may work on cytokines, chemokines, growth factors, growth factor receptors, and cell adhesion molecules. These proteinases not only involve in physiologic process, but also in pathologic conditions as cancer and inflammation disease 22-24. MMPs classification based on substrate specificity and primary structural domain result in collagenases, gelatinases, matrilysins, membranous type and other type MMP 25.

MMPs are able to degrade extracellular matrix and nonmatrix susbtrates. Enzyme regulation is initiated in transcription and translation level, zymogen activation, inhibition by extracellular or endogenous inhibitor, extracellular or subcellular localization and endocytosis internalization 26,27. Generally, MMPs are secreted in zymogen form and then activated in extracellular space by cysteine switch cleavage. MMPs activation creates proteinase network system in tissue. Once activated, MMPs are regulated by common protease inhibitor (a2 macroglobulin and a1-antiprotease) and also specific TIMP 26.

\section{MMP-9}

MMP-9 or gelatinase B are produced by various cell including epithelium cell, fibroblast, keratinocytes, dendritic cells, macrophages, granulocyes and T cell 25 . MMP-9 may be produced continuously or depend on inflammation signal induction of other cells. Pro-MMP secreted as inactive form and required activation with proteolysis by other MMPs or serine proteases, or even thiol oxidation of reactive oxygen species ${ }^{28}$.

MMP-9 may activate and change cytokines such as IL-8 and TGF- $\beta$ into active form, membrane-bound protein, transmembrane and extracellular molecules ${ }^{29}$. By degrading MBP (myelin based protein), MMP-9 increase neuroinflammation and produce encephalitogenic peptides. Shortening of ICAM-1 lead to inactivation of its adhesion function and protection from cytotoxic T cell and NK cell. By occludin and cadherin degradation in tight junction, MMP-9 is able to regulate epithelium barrier permeability 8,30 . In intracellular, MMP-9 may work on vesicle, mitochondria, cytoplasm and nucleus protein 29.

Angiogenesis role of MMP-9 is by stimulating VEGF secretion from glia cell and astrocyte 31. MMP-9 also mediates new vessel formation by proteolytic degradation of basal membrane protein, migration and proliferation of endothelial cell. Proinflammatory cytokines also lead to neovascularization by directly activate endothelial cells and indirectly by inducing proangiogenic mediator from endothelial cell 17 .

\section{MMP-9 IN DIABETIC RETINOPATHY}

There is a positive correlation of MMP-9 with diabetic retinopathy severity ${ }^{32}$. Experimental studies of diabetic mice shown decreased diabetic retinopathy risk in MMP-9 gene suppression ${ }^{6}$. Constant hyperglycaemia condition result on increased MMP-9 production from endothelial cell, vitreous humor and retinal pigmented epithelium 5,7,8,33. This is affected by AGEs formation and oxidative stress in diabetic circulation 5,34 .

MMP-9 involve in various mechanisms of diabetic retinopathy from blood-retinal barrier disruption, inflammation, neovascularization, mitochondrial damage and cell apoptosis 35. By occludin and cadherin degradation in retinal endothelial cell tight junction, MMP-9 impair barrier of blood-retina. Occludin is an important protein in cortical actin preparation in maintaining barrier stability 30 . Endothelial leakage also allows leukocyte migration and infiltration mediated by VCAM- 1 and ICAM- 1 activity and chemotaxis effect MMP-9. These will bring leukostasis and blood vessel occlusion in retina 36,37. Permeability vascular changes will facilitate inflammatory cytokines and chemokines entry into retinal tissue complex $32,35,38$.

Intracellularly, MMP-9 affected by H-Ras may induce Raf$1 /$ MEK activation result in dysfunction of mitochondrial membrane permeability. Cytochrome $-\mathrm{C}$ leakage to cytosol can cause apoptosis of retina capillary cells 39 . MMP-9 is known to be able to move into mitochondria mediated by Hsp70/Hsp60 and damage it from within 40. Expression of MMP-9 has an effect on apoptotic protein expressions such as Bax2, Bcl2, PARP-1 and caspase-3 in retinal Muller cell. This protein has been known in decreasing viability and apoptosis induction 7 .

The proangiogenic activity of MMP-9 is proved by its activity with VEGF and TGF- $\beta$. There is a reciprocal relationship of MMP-9 and VEGF in mediating angiogenesis of retinopathy. Upregulation of VEGF mediated by MMP-9 leads to neovascularization while decreased level of MMP-9 lowering VEGF production. In the vitrous humor of PDR patients, level of VEGF and MMP-9 was found significantly higher 31,41. In retinal vein occlusion cases, TGF- $\beta$ and MMP- 9 concentration was found higher in vitreous humor than control group. The ability of TGF- $\beta$ and MMP-9 in cytoskeleton arrangement and basalic membrane proteolysis resulting in tissue remodeling and angiogenesis 42 .

\section{CONCLUSION}

Diabetic retinopathy occurs in complex mechanism involving retinal neurovascular components. Hyperglycaemia constant trigger oxidative stress dan increased MMP-9 activity. MMP9 role in retinopathy by occludin degradation and 
endothelial cell apoptosis that leads to blood-retinal barrier disruption, retina Muller cell damages and angiogenesis.

\section{REFERENCES}

1. Yau JWY, Rogers SL, Kawasaki R, Lamoureux EL, Kowalski JW, Bek T, et al. Global prevalence and major risk factors of diabetic retinopathy. Diabetes Care. 2012; 35(3):556-64.

2. Lee R, Wong TY, Sabanayagam C. Epidemiology of diabetic retinopathy, diabetic macular edema and related vision loss. Eye Vis [Internet]. 2015; 2(1):1-25. Available from: http://dx.doi.org/10.1186/s40662-015-0026-2

3. Cho NH, Shaw JE, Karuranga S, Huang Y, da Rocha Fernandes JD, Ohlrogge AW, et al. IDF Diabetes Atlas: Global estimates of diabetes prevalence for 2017 and projections for 2045. Diabetes Res Clin Pract [Internet]. 2018; 138:271-81. Available from: https://doi.org/10.1016/j.diabres.2018.02.023

4. Jenkins AJ, Joglekar M V., Hardikar AA, Keech AC, O'Neal DN, Januszewski AS. Biomarkers in diabetic retinopathy. Rev Diabet Stud. 2015; 12(1-2):159-95.

5. Kowluru RA. Role of matrix metalloproteinase-9 in the development of diabetic retinopathy and its regulation by H-Ras. Investig Ophthalmol Vis Sci. 2010; 51(8):4320-6.

6. Kowluru RA, Mohammad G, Dos Santos JM, Zhong Q. Abrogation of MMP-9 gene protects against the development of retinopathy in diabetic mice by preventing mitochondrial damage. Diabetes. 2011; 60(11):3023-33.

7. Chen Y, Wang W, Liu F, Tang L, Tang R, Li W. Apoptotic effect of mtrix metalloproteinases 9 in the development of diabetic retinopathy. Int J Clin Exp Pathol. 2015; 8(9):10452-9.

8. Giebel SJ, Menicucci G, McGuire PG, Das A. Matrix metalloproteinases in early diabetic retinopathy and their role in alternation of the blood-retinal barrier. Lab Investig. 2005; 85(5):597-607.

9. Opdenakker G, Abu El-Asrar A. Metalloproteinases mediate diabetesinduced retinal neuropathy and vasculopathy. Cell Mol Life Sci [Internet]. 2019; 76(16):3157-66. Available from: https://doi.org/10.1007/s00018-019-03177-3

10. Antonetti DA, Klein R, Gardner TW. Diabetic retinopathy. N Engl J Med. 2012; 366:1227-39.

11. Altmann C, Schmidt MHH. The role of microglia in diabetic retinopathy: Inflammation, microvasculature defects and neurodegeneration. Int J Mol Sci. 2018;

12. Gardner TW, Davila JR. The Neurovascular Unit and the Pathophysiologic Basis of Diabetic Retinopathy. Graefes Arch Clin Exp Ophtalmol. 2017; 255(1):1-6.

13. Flaxel CJ, Adelman RA, Bailey ST, Fawzi A, Lim JI, Vemulakonda GA, et al. Diabetic Retinopathy Preferred Practice Pattern $®$. Ophthalmology. 2020; 127(1):P66-145.

14. Kilpatrick ES, Rigby AS, Atkin SL, Frier BM. Does severe hypoglycaemia influence microvascular complications in Type 1 diabetes? An analysis of the Diabetes Control and Complications Trial database. Diabet Med. 2012; 29(9):1195-8.

15. Brownlee $M$. The pathobiology of diabetic complications: A unifying mechanism. Diabetes. 2005; 54(6):1615-25.

16. Duh EJ, Sun JK, Stitt AW. Diabetic retinopathy: current understanding, mechanisms, and treatment strategies. JCI insight. 2017; 2(14):1-13.

17. Rübsam $A$, Parikh S, Fort PE. Role of inflammation in diabetic retinopathy. Int J Mol Sci. 2018; 19(4):1-31.

18. Altmanc C, Schmidt MH. the role of microglia in Diabetic Retinopathy : inflammation, microvasculature defect and neurodegeneration. Int J Mol Sci. 2018; 19.

19. Kaur C, Rathnasamy G, Foulds WS, Ling E-A. Cellular and Molecular Mechanisms of Retinal Ganglion Cell Death in Hypoxic-Ischemic Injuries. J Neurol Exp Neurosci. 2015; 10-9.

20. Cauwe B, Steen PEV Den, Opdenakker G. The biochemical, biological, and pathological kaleidoscope of cell surface substrates processed by matrix metalloproteinases. Vol. 42, Critical Reviews in Biochemistry and Molecular Biology. 2007.113-185 p.

21. Simó R, Sundstrom JM, Antonetti DA. Ocular anti-VEGF therapy for diabetic retinopathy: The role of VEGF in the pathogenesis of diabetic retinopathy. Diabetes Care. 2014; 37(4):893-9.

22. Parks WC, Wilson CL, López-Boado YS. Matrix metalloproteinases as modulators of inflammation and innate immunity. Nat Rev Immunol. 2004; 4(8):617-29.

23. Toriseva M, Kähäri VM. Proteinases in cutaneous wound healing. Cell Mol Life Sci. 2009; 66(2):203-24.

24. Kessenbrock K, Placks V, Werb Z. Matrix Metalloproteinases:
Regulators of the Tumor Microenvironment. Cell. 2015 Feb; 135(2):612-5.

25. Cui N, Hu M, Khalil RA, Mol P, Transl B, Author S. Biochemical and Biological Attributes of Matrix Metalloproteinases HHS Public Access Author manuscript. Prog Mol Biol Transl Sci [Internet]. 2017; 147(617):1-73. Available from: https://www.ncbi.nlm.nih.gov/pmc/articles/PMC5430303/pdf/nih ms856854.pdf

26. Nissinen L, Kähäri V-M. Matrix metalloproteinases in inflammation. Biochim Biophys Acta - Gen Subj. 2014; 1840(8):2571-80.

27. Djuric T, Zivkovic M. Overview of MMP Biology and Gene Associations in Human DIseases. In: Intech [Internet]. Belgrade; 2017. p. 3-35. Available from: https://www.intechopen.com/books/advanced-biometrictechnologies/liveness-detection-in-biometrics

28. Jobin PG, Butler GS, Overall CM. New intracellular activities of matrix metalloproteinases shine in the moonlight. Biochim Biophys Acta Mol Cell Res [Internet]. 2017; 1864(11):2043-55. Available from: http://dx.doi.org/10.1016/j.bbamcr.2017.05.013

29. Cauwe B, Martens E, Proost P, Opdenakker G. Multidimensional degradomics identifies systemic autoantigens and intracellular matrix proteins as novel gelatinase B/MMP-9 substrates. Integr Biol. 2009; 1(5-6):404-26.

30. Cummins PM. Occludin: One Protein, Many Forms. Mol Cell Biol. 2012; 32(2):242-50.

31. Abu El-Asrar AM, Mohammad G, Nawaz MI, Siddiquei MM, Van Den Eynde K, Mousa A, et al. Relationship between vitreous levels of matrix metalloproteinases and vascular endothelial growth factor in proliferative diabetic retinopathy. PLoS One. 2013; 8(12):1-11.

32. Jayashree K, Yasir M, Senthilkumar GP, Ramesh Babu K, Mehalingam V, Mohanraj PS. Circulating matrix modulators (MMP-9 and TIMP-1) and their association with severity of diabetic retinopathy. Diabetes Metab Syndr Clin Res Rev [Internet]. 2018; 12(6):869-73. Available from: https://doi.org/10.1016/j.dsx.2018.05.006

33. De Groef L, Andries L, Lemmens K, Van Hove I, Moons L. Matrix metalloproteinases in the mouse retina: A comparative study of expression patterns and MMP antibodies Retina. BMC Ophthalmol [Internet]. 2015;15(1):1-16. Available from: http://dx.doi.org/10.1186/s12886-015-0176-y

34. Chen YD, Xu X, Xia X, Wu H, Liu K, Zheng Z, et al. MMP9 is involved in glycation end-products induced increase of retinal vascular permeability in rats and the therapeutic effect of minocycline. Curr Eye Res. 2008;33(11-12):977-83.

35. Kowluru RA, Mishra M. Regulation of Matrix Metalloproteinase in the Pathogenesis of Diabetic Retinopathy [Internet]. 1st ed. Vol. 148, Progress in Molecular Biology and Translational Science. Elsevier Inc.; 2017. 67-85 p. Available from: http://dx.doi.org/10.1016/bs.pmbts.2017.02.004

36. Kowluru RA, Zhong Q, Santos JM. Matrix metalloproteinases in diabetic retinopathy: potential role of MMP-9. Expert Opin Investig Drugs [Internet]. 2012; 21(6):797-805. Available from: https://www.ncbi.nlm.nih.gov/pmc/articles/PMC3624763/pdf/nih ms412728.pdf

37. Hannocks MJ, Zhang X, Gerwien $H$, Chashchina A, Burmeister M, Korpos E, et al. The gelatinases, MMP-2 and MMP-9, as fine tuners of neuroinflammatory processes. Matrix Biol [Internet]. 2019;7576:102-13. Available from: https://doi.org/10.1016/j.matbio.2017.11.007

38. Ghulam Mohammad, Kowluru RA. Diabetic Retinopathy and Signaling Mechanism for Activation of Matrix Metalloproteinase-9. J Cell Physiol [Internet]. 2012; 227(3):1052-61. Available from: https://www.ncbi.nlm.nih.gov/pmc/articles/PMC3624763/pdf/nih ms412728.pdf

39. Santos JM, Tewari S, Lin JY, Kowluru RA. Interrelationship between activation of matrix metalloproteinases and mitochondrial dysfunctiom in the development of diabetic retinopathy. Biochem Biophys Res Commun [Internet]. 2013; 438(4):1-12. Available from: https://www.ncbi.nlm.nih.gov/pmc/articles/PMC3624763/pdf/nih ms412728.pdf

40. Tewari S, Santos JM, Kowluru RA. Damaged mitochondrial DNA replication system and the development of diabetic retinopathy. Antioxidants Redox Signal. 2012; 17(3):492-504.

41. Di Y, Nie QZ, Chen XL. Matrix metalloproteinase-9 and vascular endothelial growth factor expression change in experimental retinal neovascularization. Int J Ophthalmol. 2016; 9(6):804-8.

42. Tuuminen R, Loukovaara S. High intravitreal TGF- $\beta 1$ and MMP-9 levels in eyes with retinal vein occlusion. Eye. 2014; 28(9):1095-9. 